\title{
BMP4 promotes mouse iPS cell differentiation to male germ cells via Smad1/5, Gata4, Id1 and Id2
}

\author{
Shi Yang ${ }^{1}$, Qingqing Yuan², Minghui Niu², Jingmei Hou², Zijue Zhu ${ }^{3}$ Min Sun², Zheng Li $^{3}$ \\ and Zuping $\mathrm{He}^{2,4,5,6}$ \\ ${ }^{1}$ Department of Urology, ${ }^{2}$ State Key Laboratory of Oncogenes and Related Genes, Renji-Med X Clinical Stem Cell \\ Research Center, Ren Ji Hospital, School of Medicine, Shanghai Jiao Tong University, Shanghai Human Sperm \\ Bank, Shanghai, China, ${ }^{3}$ Department of Andrology, Urologic Medical Center, Shanghai General Hospital, \\ Shanghai Jiao Tong University, Shanghai, China, ${ }^{4}$ Department of Urology, Ren Ji Hospital, School of Medicine, \\ Shanghai Jiao Tong University, Shanghai Institute of Andrology, Shanghai, China, ${ }^{5}$ Shanghai Key Laboratory of \\ Assisted Reproduction and Reproductive Genetics, Shanghai, China and ${ }^{6}$ Shanghai Key Laboratory of \\ Reproductive Medicine, Shanghai, China
}

Correspondence should be addressed to Z He; Email: zupinghe@sjtu.edu.cn

\begin{abstract}
Generation of male germ cells from pluripotent cells could provide male gametes for treating male infertility and offer an ideal model for unveiling molecular mechanisms of spermatogenesis. However, the influence and exact molecular mechanisms, especially downstream effectors of BMP4 signaling pathways, in male germ cell differentiation of the induce pluripotent stem (iPS) cells, remain unknown. This study was designed to explore the role and mechanism of BMP4 signaling in the differentiation of mouse iPS cells to male germ cells. Embryoid body (EB) formation and recombinant BMP4 or Noggin were utilized to evaluate the effect of BMP4 on male germ cell generation from mouse iPS cells. Germ cell-specific genes and proteins as well as the downstream effectors of BMP4 signaling pathway were assessed using real-time PCR and Western blots. We found that BMP4 ligand and its multiple receptors, including BMPR1a, BMPR1b and BMPR2, were expressed in mouse iPS cells. Real-time PCR and Western blots revealed that BMP4 could upregulate the levels of genes and proteins for germ cell markers in iPS cells-derived EBs, whereas Noggin decreased their expression in these cells. Moreover, Smad1/5 phosphorylation, Gata4 transcription and the transcripts of Id 1 and Id2 were enhanced by BMP4 but decreased when exposed to Noggin. Collectively, these results suggest that BMP4 promotes the generation of male germ cells from iPS cells via Smad1/5 pathway and the activation of Gata4, Id1 and Id2. This study thus offers novel insights into molecular mechanisms underlying male germ cell development.

Reproduction (2017) 153 211-220
\end{abstract}

\section{Introduction}

In the last few years, several groups have shown that embryonic stem (ES) cells and the induced pluripotent stem (iPS) cells can differentiate into male germ cells (Kee et al. 2009, Easley et al. 2012, Lim et al. 2014, Ramathal et al. 2014). We have previously demonstrated that mouse iPS cells have the potential to give rise to male germ cells in vitro (Yang et al. 2012, Li et al. 2013). Numerous studies have reported that bone morphogenetic proteins (BMPs) have essential function in primordial germ cell (PGC) specification and germ cell lineage commitment from pluripotent cells (Wei et al. 2008, Hiller et al. 2011). However, little is known about the role and mechanisms of BMP4 signaling in generating male germ cells from iPS cells.

BMPs belong to members of transforming growth factor $\beta$ (TGF- $\beta$ ) superfamily, and they play various kinds of roles in regulating the self-renewal of stem cells and developmental processes, including neural, hematopoietic, cardiomyogenic and hepatic lineage formation (Varga \& Wrana 2005, Fei et al. 2010). As examples, BMPs are involved in directing both selfrenewal and differentiation of ES cells. BMPs, working with LIF, maintain the self-renewal state of mouse ES cells (Ying et al. 2003, Li et al. 2012). As a mesoderm inducer, BMPs induce both ES and iPS cells to differentiate to PGCs (Wei et al. 2008, Saitou \& Yamaji 2010, Panula et al. 2011). Interestingly, BMPs could efficiently coax germ cell generation from human ES or iPS cells (Panula et al. 2011). BMPs can also regulate both spermatogonial proliferation and differentiation in vitro or in vivo. For instance, BMP4 exerts both mitogenic and differentiation effect on undifferentiated spermatogonia (Hu et al. 2004, Itman \& Loveland 2008). Collectively, as 
a pivotal factor, BMPs might be closely associated with ES or iPS cell differentiation into all three germ layers and eventually germ cells (Li \& Chen 2013).

BMPs initiate the signal through binding to their multiple receptors, including transmembrane type I receptors BMPR1a or BMPR1b and type II receptor BMPR2, which phosphorylates receptor-activated Smads (R-Smads, Smad1/5/8) to form a complex with common Smad (co-Smad and Smad4). The Smad complex translocates into the nucleus and regulates downstream target gene expression through other DNAbinding factors and transcription factors in the nucleus (Shi \& Massague 2003, Fei et al. 2010). Despite progress in classical BMP4 signaling cascades, the influence and exact molecular mechanisms, especially downstream effectors of BMP4 signaling pathways, in male germ cell differentiation of iPS cells, remain to be elucidated. The generation of male germ cells from iPS cells offers an ideal system for exploring molecular mechanisms underlying germline formation. To better understand the role and mechanisms of BMP4 signaling in regulating the differentiation of iPS cells into male germ cells, here we have for the first time examined the effect of BMP4 and its inhibitor Noggin on the male germ cell lineage commitment of mouse iPS cells. Moreover, we probed the expression, function and signaling transduction pathway of BMP4 during the differentiation of iPS cells into male germ cells.

\section{Materials and methods}

\section{Mouse iPS cells and EB culture with BMP4 and/or Noggin}

The mouse iPS cell line (Tg-GFP-miPS11.1) was a kind gift from Prof. Ying Jin, Shanghai Jiao Tong University School of Medicine, Shanghai, China. These iPS cells were generated from neural progenitor cells of EGFP transgenic C57BL/6J mice via retroviral transfer of Oct4/Sox2/C-Myc/KIf4 (Li et al. 2009). Notably, this cell line has been demonstrated to be germline competent (Li et al. 2009). iPS cells were cultured in the medium according to the procedure as described previously (Yang et al. 2012). Briefly, iPS cells were co-cultured on feeder cells, namely irradiated mouse embryonic fibroblasts (MEFs), in high glucose DMEM containing 15\% fetal bovine serum (FBS; Hyclone, Logan, UT, USA), $100 \mathrm{mg} / \mathrm{mL}$ leukemia inhibiting factor (LIF; Millipore), $100 \mathrm{U} / \mathrm{mL}$ penicillin plus $100 \mathrm{mg} / \mathrm{mL}$ streptomycin (Gibco), $2 \mathrm{mM}$ L-glutamine (Gibco), $0.1 \mathrm{mM} \beta$-mercaptoethanol (Gibco) and $0.1 \mathrm{mM}$ non-essential amino acids (NEAA; Gibco). The cells were passaged every $2-3$ days, and culture was maintained at $37^{\circ} \mathrm{C}$ in a humidified incubator with $5 \% \mathrm{CO}_{2}$.

Embryoid bodies (EBs) were formed by hanging drop and suspension culture method as follows: iPS cells were digested to become single cells and transferred to low-attachment dishes containing the above culture medium without LIF. EBs were treated without or with 10,50 and $100 \mathrm{ng} / \mathrm{mL} \mathrm{BMP4}$ (R\&D) and/or 10, 50 and $100 \mathrm{ng} / \mathrm{mL}$ Noggin (R\&D) for 7 days.

\section{RNA extraction, RT-PCR and quantitative real-time PCR}

Total RNA was extracted from iPS cells and EBs derived from iPS cells using TRIzol (Invitrogen). After DNase treatment to remove potential contamination with genomic DNA, $1 \mu \mathrm{g}$ of total RNA was transcribed into cDNA using First-Strand cDNA Synthesis Kit (Fermentas, Waltham, MA, USA). PCR was performed according to the protocol as described previously (Guo et al. 2015, Liu et al. 2015), and quantitative real-time PCR was performed using SYBR Green master mix and a 7500 Fast Real-Time PCR System (Applied Biosystems) pursuant to the method as described previously (Yang et al. 2014). The primer sequences of genes used for PCR and real-time PCR were designed and listed in Tables 1 and 2 respectively. Realtime PCR products were quantified using the comparative $C_{t}$ (threshold cycle) method. The threshold of cycle values was normalized against the threshold value of mouse Gapdh.

\section{Immunocytochemistry}

The expression of BMP4 and its receptors as well as germ cell-specific markers in EB cells was obtained by immunocytochemistry according to the procedure described previously (Liu et al. 2015). Briefly, iPS cells were fixed in 4\%

Table 1 Primers of genes used for RT-PCR.

\begin{tabular}{|c|c|c|c|c|}
\hline Genes & Primer sequences & Product size $(b p)$ & $\boldsymbol{T}_{\mathrm{m}}\left({ }^{\circ} \mathrm{C}\right)$ & Number of cycles \\
\hline \multirow[t]{2}{*}{ Bmp4 } & Forward 5'-TAGTCCCAAGCATCACCC-3' & 354 & 56 & 35 \\
\hline & Reverse 5'-TCTCAGCGGCATCCAC-3' & & & \\
\hline \multirow[t]{2}{*}{ Bmpr1a } & Forward 5'-TCAGGGAGAAACCACAT-3' & 180 & 50 & 35 \\
\hline & Reverse 5'-CTGCCATCAAAGAACG-3' & & & \\
\hline \multirow[t]{2}{*}{ Bmpr1b } & Forward 5'-TGGATGGGAAAGTGGC-3' & 456 & 53 & 35 \\
\hline & Reverse 5'-GGTGTTGGGTGGGATG-3' & & & \\
\hline \multirow[t]{2}{*}{ Bmpr2 } & Forward 5'-GGAGCGAAATGAAGGG-3' & 470 & 53 & 35 \\
\hline & Reverse 5'-CACCGATGTGAGACCAA-3' & & & \\
\hline \multirow[t]{2}{*}{ Oct4 } & Forward 5'-ATGGCATACTGTGGACCTCA-3' & 236 & 58 & 35 \\
\hline & Reverse 5'-AGCAGCTTGGCAAACTGTTC-3' & & & \\
\hline \multirow[t]{2}{*}{ Sox2 } & Forward 5'-GCGGAGTGGAAACTTTTGTCC-3' & 156 & 60 & 35 \\
\hline & Reverse 5'-GGGAAGCGTGTACTTATCCTTCT-3' & & & \\
\hline \multirow{2}{*}{ Nanog } & Forward 5'-TCGCССТTCСТСТGAAGAC-3' & 195 & 60 & 35 \\
\hline & Reverse 5'-TGCTTCTGAAACCTGTCCTTGA-3' & & & \\
\hline \multirow[t]{2}{*}{ Gapdh } & Forward 5'-TCTCCTGCGACTTCAACA-3' & 178 & 55 & 35 \\
\hline & Reverse 5'-TGGTCCAGGGTTTCTTACT-3' & & & \\
\hline
\end{tabular}


Table 2 Primers of genes used for real-time PCR.

\begin{tabular}{|c|c|c|c|c|}
\hline Genes & Primer sequences & Product size $(b p)$ & $T_{\mathrm{m}}\left({ }^{\circ} \mathrm{C}\right)$ & Number of cycles \\
\hline Blimp1 & $\begin{array}{l}\text { Forward 5'-CTTCTCTTGGAAAAACGTGTGGG-3' } \\
\text { Reverse 5'-TCATATCAGCGTCCTCCATGT-3' }\end{array}$ & 203 & 60 & 40 \\
\hline Fragilis & $\begin{array}{l}\text { Forward 5'-CTCCATCCTTTGCCCTCCAG-3' } \\
\text { Reverse 5'-GTAGTTTGGGGGCTGTCCTC-3' }\end{array}$ & 100 & 60 & 40 \\
\hline Stella & $\begin{array}{l}\text { Forward 5'-GGGAAGTTCAAAGCGCCTTTC-3' } \\
\text { Reverse 5'-ACTCATTTCCTTCGAGCCTTTTT-3' }\end{array}$ & 129 & 60 & 40 \\
\hline Vasa & $\begin{array}{l}\text { Forward 5'-ATTCTTGGAAGTCAGAAGCAGAAG-3' } \\
\text { Reverse 5'-CTGGTTGACCAATTCTCGAGT-3' }\end{array}$ & 467 & 60 & 40 \\
\hline Dazl & $\begin{array}{l}\text { Forward 5'-TCTGCCACAACTTCTGAGGC-3' } \\
\text { Reverse 5'-CCTGATTTCGGTTTCATCCATCC-3' }\end{array}$ & 168 & 60 & 40 \\
\hline Kit & $\begin{array}{l}\text { Forward 5'-CCCGACGCAACTTCCTTA-3' } \\
\text { Reverse 5'-CGCTTCTGCCTGCTCTTC-3' }\end{array}$ & 385 & 58 & 40 \\
\hline Boule & $\begin{array}{l}\text { Forward 5'-CCATTCCTATATCTGCAACCTTCT-3' } \\
\text { Reverse 5-GGTCAGAATAAGGCTCTGGAAC-3' }\end{array}$ & 124 & 58 & 40 \\
\hline Scp 1 & $\begin{array}{l}\text { Forward 5'-GAGCCAATGAGCAGACTGTAT-3' } \\
\text { Reverse 5-CGCTGGGCTTCAATTATCTTTC-3' }\end{array}$ & 137 & 58 & 40 \\
\hline Scp3 & $\begin{array}{l}\text { Forward 5'-CCAGGTTTCCTCAGATGCTT-3' } \\
\text { Reverse 5-AAGGTGGCTTCCCAGATTTC-3' }\end{array}$ & 123 & 57 & 40 \\
\hline Crebbp & $\begin{array}{l}\text { Forward 5'-TGTGCATACTCAGCCTCCTG-3' } \\
\text { Reverse 5-TGGGAACTGGTTTCAGCACT-3' }\end{array}$ & 105 & 60 & 40 \\
\hline Gata4 & $\begin{array}{l}\text { Forward 5'-CAGTTGTGGTGGTGGGTTT-3' } \\
\text { Reverse 5-AGGGCAGGGCTTCTATGTCT -3' }\end{array}$ & 125 & 60 & 40 \\
\hline FOS & $\begin{array}{l}\text { Forward 5'-GGATTTGACTGGAGGTCTGC-3' } \\
\text { Reverse 5-TTGCTGATGCTCTTGACTGG-3' }\end{array}$ & 120 & 60 & 40 \\
\hline Jun & $\begin{array}{l}\text { Forward 5'-ACAGACAGACGGACGGACTT-3' } \\
\text { Reverse 5-GAAGGGACTCTCCAAATGCTC-3' }\end{array}$ & 147 & 58 & 40 \\
\hline Id 1 & $\begin{array}{l}\text { Forward 5'-GCATCTTGTGTCGCTGAGG-3' } \\
\text { Reverse 5-GCGGTAGTGTCTTTCCCAGA-3' }\end{array}$ & 118 & 60 & 40 \\
\hline$I d 2$ & $\begin{array}{l}\text { Forward 5'-CCCGATGAGTCTGCTCTACA-3' } \\
\text { Reverse 5-GCAGGATTTCCATCTTGGTC-3' }\end{array}$ & 104 & 59 & 40 \\
\hline Id 3 & $\begin{array}{l}\text { Forward 5'-GCATGGATGAGCTTCGATCT-3' } \\
\text { Reverse 5-CTCTTCAGGCCACCCAAGT-3' }\end{array}$ & 111 & 60 & 40 \\
\hline Id 4 & $\begin{array}{l}\text { Forward 5'-CAGTGCGATATGAACGACTGC-3' } \\
\text { Reverse 5-GACTTTCTTGTTGGGCGGGAT-3' }\end{array}$ & 72 & 60 & 40 \\
\hline Gapdh & $\begin{array}{l}\text { Forward 5'-AGAACATCATCCCTGCATCC-3' } \\
\text { Reverse 5'-CACATTGGGGGTAGGAACAC-3' }\end{array}$ & 110 & 58 & 40 \\
\hline
\end{tabular}

paraformaldehyde (PFA) and permeabilized with $0.4 \%$ Triton $X-100$. The cells were blocked with $10 \%$ serum and incubated with primary antibodies against BMP4 (Abcam), BMPR1A (Santa Cruz), BMPR1B (Santa Cruz), BMPR2 (Santa Cruz), PRDM1 (Abnova, Taipei, Taiwan) and VASA (Abcam) overnight

Table 3 Detailed information on the antibodies used for immunocytochemistry and Western blots.

\begin{tabular}{lll}
\hline Antibodies & $\begin{array}{l}\text { Sources } \\
\text { (product number) }\end{array}$ & Dilutions \\
\hline BMP4 & Abcam (ab39733) & $1: 200$ (Immunocytochemistry) \\
BMPR1A & Santa Cruz (sc-20736) & $1: 200$ (Immunocytochemistry) \\
BMPR1B & Santa Cruz (sc-25455) & $1: 200$ (Immunocytochemistry) \\
BMPR2 & Santa Cruz (sc-20737) & $1: 200$ (Immunocytochemistry) \\
PRDM1 & Abnova (PAB13234) & $1: 200$ (Immunocytochemistry) \\
& & $1: 1000$ (Western blots) \\
VASA & Abcam (ab13840) & $1: 200$ (Immunocytochemistry) \\
& & $1: 1000$ (Western blots) \\
DAZL & Abcam (ab34139) & $1: 1000$ (Western blots) \\
UCHL1 & AbD Serotec (AHP739) & $1: 1000$ (Western blots) \\
GFRA1 & Santa Cruz (sc-10716) & $1: 1000$ (Western blots) \\
KIT & Abcam (ab62154) & $1: 1000$ (Western blots) \\
phospho- & Cell signaling & $1: 1000$ (Western blots) \\
\multicolumn{1}{c}{ Smad1/5 } & (mAb \#9516) & $1: 1000$ (Western blots) \\
Smad5 & $\begin{array}{c}\text { Cell signaling } \\
\text { (mAb \#12534) }\end{array}$ \\
ACTB & $\begin{array}{c}\text { Proteintech } \\
\text { (20536-1-AP) }\end{array}$ \\
& & $1: 2000$ (Western blots) \\
\hline
\end{tabular}

at $4^{\circ} \mathrm{C}$. The detailed information on antibodies was shown in Table 3 . The cells were then incubated by goat anti-rabbit Alexa Fluor 594 (red)-labeled secondary antibody (Invitrogen) for $1 \mathrm{~h}$. DAPI was used to label cell nuclei, and images were captured with a fluorescence microscope (Leica).

\section{Western blots}

The EBs derived from iPS cells were lysed using the RIPA buffer (Santa Cruz) containing a cocktail of protease inhibitors (Roche). Cell lysates were cleared by centrifugation at $12,000 \mathrm{~g}$, and the concentrations of total proteins were measured by BCA kit (Dingguo Company, Beijing, China). Twenty micrograms of total protein were separated by SDSPAGE and transferred to polyvinylidene difluoride membranes. After blocking with $5 \%$ BSA and $0.1 \%$ Tween20 for $1 \mathrm{~h}$ at room temperature, membranes were probed with primary antibodies, including PRDM1 (Abnova), VASA (Abcam), DAZL (Abcam), UCHL1 (AbD Serotec Kidlington, UK), GFRA1 (Santa Cruz), KIT (Abcam), phospho-Smad1/5 (Cell signaling), Smad5 (Cell signaling) and ACTB (beta-actin, Proteintech) overnight at $4{ }^{\circ} \mathrm{C}$. The detailed information on antibodies was shown in Table 3. The blots were incubated with HRP-conjugated antirabbit or anti-goat IgG polyclonal secondary antibodies (Santa Cruz) at 1:2500 dilution for $1 \mathrm{~h}$ at room temperature. After 
extensive washes with TBST, the blots were visualized using an enhanced-chemiluminescent detection kit (Santa Cruz).

\section{Statistical analysis}

All the values were presented as mean \pm S.E.M. from at least three independent experiments. Statistical differences were evaluated using the analysis of variance (ANOVA), and $P<0.05$ was considered statistically different.

\section{Results}

\section{BMP4 and its receptors were expressed in mouse iPS cells}

To examine whether BMP4 signals via an autocrine or a paracrine pathway in mouse iPS cells, RT-PCR and immunocytochemistry were performed to detect the expression of BMP4 and its multiple receptors. As shown in Fig. 1A, the mRNA of Bmp4 and its receptors, including Bmpr 1a, Bmpr $1 b$ and Bmpr2, were detectable in iPS cells. Immunocytochemistry further showed

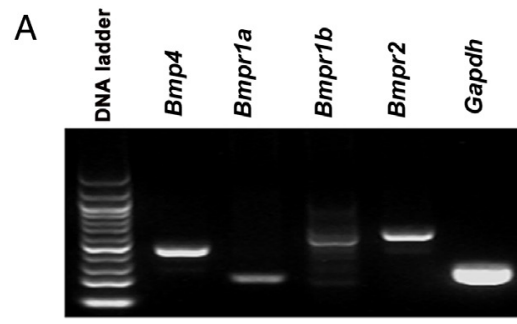

B

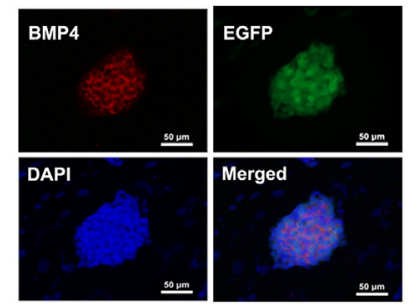

C
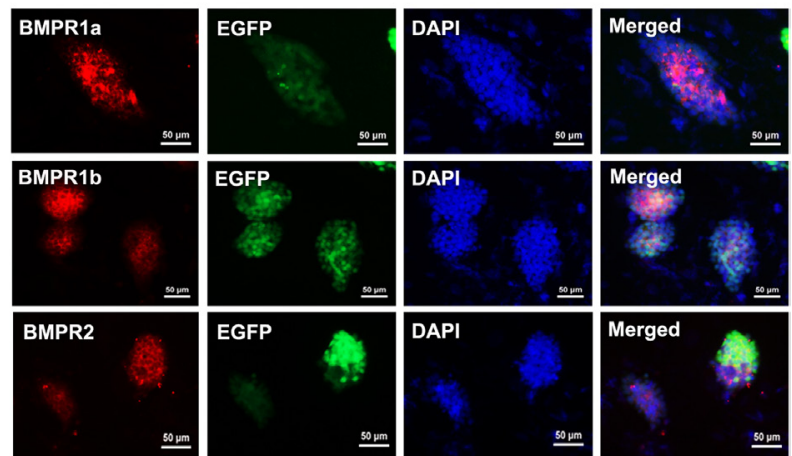

Figure 1 Expression of BMP4 and its receptors BMPR1a, BMPR1b and BMPR2 in mouse iPS cells. (A) RT-PCR displayed the transcripts of Bmp4, Bmpr1a, Bmpr1b and Bmpr2 in iPS cells. Gapdh served as the loading control of total RNA. (B and C) Immunohistochemistry revealed the translation of BMP4 (B), BMPR1a, BMPR1b and BMPR2 (C) in iPS cells. The expression of EGFP in these cells was also shown. Scale bars in $(B)$ and $(C)=50 \mu \mathrm{m}$. both BMP4 ligand (Fig. 1B) and its three receptors, i.e. BMPR1a, BMPR1b and BMPR2 were expressed in iPS cells (Fig. 1C). These results implicate that BMP4 acts via an autocrine or paracrine manner in mouse iPS cells.

\section{BMP4 affected male germ cell differentiation of iPS cells}

To determine the role of BMP4 in regulating the differentiation of mouse iPS cells, expression levels of germ cell-specific genes in iPS cells, EBs without treatment (Control), EBs treated with $100 \mathrm{ng} / \mathrm{mL}$ BMP4 or BMP4 antagonist Noggin were compared using RT-PCR. Pluripotency markers, e.g. Oct4, Sox2 and Nanog, were detected in the undifferentiated mouse iPS cells (Fig. 2A). As shown in Fig. 2B, the expression of germ cell-specific markers, including Stella and Blimp1, and hallmarks of primordial germ cells (PGCs) (Saitou et al. 2005, Wei et al. 2008, Hayashi \& Surani 2009), was

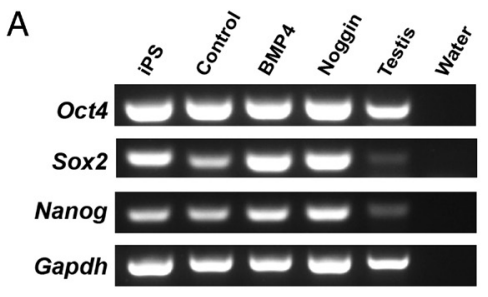

B
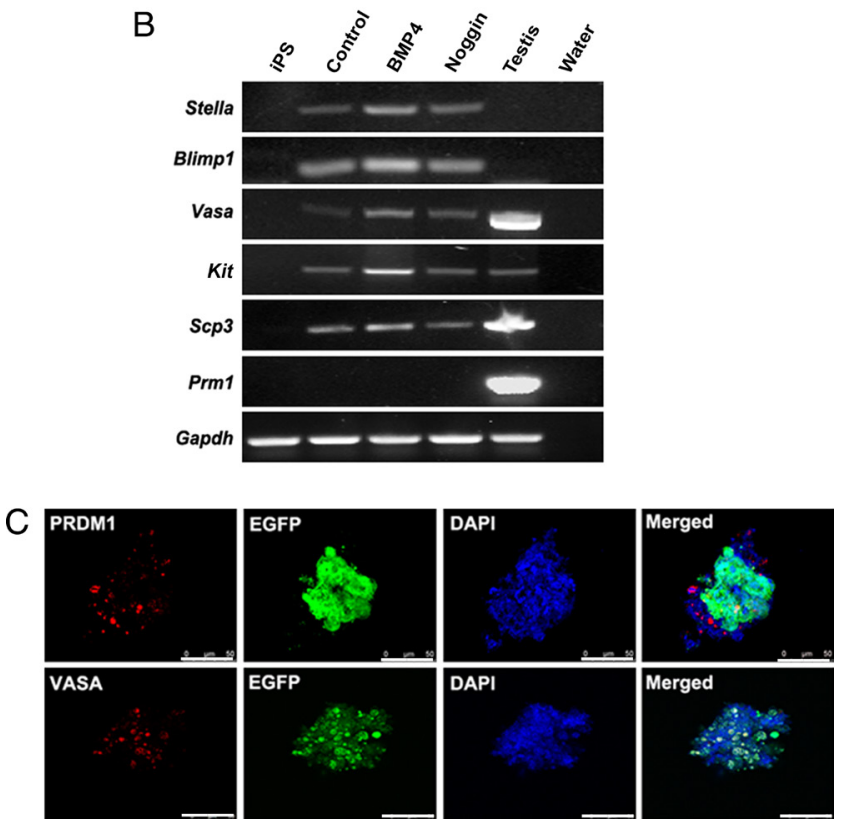

Figure 2 BMP4-induced male germ cell differentiation of mouse iPS cells. (A) RT-PCR showed mRNA expression of Oct4, Sox2 and Nanog in iPS cells, EBs without treatment (Control), EBs treated with $100 \mathrm{ng} / \mathrm{mL}$ BMP4 or Noggin, and mouse testis. (B) RT-PCR revealed mRNA expression of Stella, Blimp1, Vasa, Kit, Scp3 and Prm1 in iPS cells, EBs without treatment (Control), EBs treated with $100 \mathrm{ng} / \mathrm{mL}$ BMP4 or Noggin and testis. (C) Immunohistochemistry showed PRDM1 and VASA expression in EBs treated with $100 \mathrm{ng} / \mathrm{mL}$ BMP4. Scale bars $=50 \mu \mathrm{m}$. 
enhanced in BMP4-treated EBs compared to the untreated EBs and Noggin-treated EBs. Transcripts of male germ cell-specific gene Vasa (Silva et al. 2009) and differentiating spermatogonial marker Kit (He et al. 2007) and meiotic germ cell marker Scp3 (West et al. 2006) were upregulated in BMP4-treated EBs compared with the untreated EBs and Noggin-treated EBs. However, expression of haploid germ cell marker Prm1 (Kerr \& Cheng 2010) was undetected in BMP- or Noggin-treated EBs and -untreated EBs.

To further examine the expression of major germ cell lineage markers in iPS cell-derived cells, iPS cellderived EBs with BMP4 treatment were stained with PGC hallmark PRDM1 and male germ cell-specific marker VASA. Immunocytochemistry showed that PRDM1- and VASA-positive cells were observed in $30-40 \%$ of iPS cell-derived EBs (Fig. 2C), suggesting that iPS cells could differentiate into germ cells.

\section{BMP4 signaling promoted male germ cell differentiation of iPS cells}

To better understand the effect of BMP4 on male germ cell differentiation of iPS cells, iPS cell-derived EBs were treated without or with different concentrations of BMP4 $(10,50$ and $100 \mathrm{ng} / \mathrm{mL})$ to compare the expression changes of germ cell-specific genes and proteins. Realtime PCR revealed that the expression levels of PGC markers Blimp1 and Stella were remarkably upregulated in EBs treated with $10-100 \mathrm{ng} / \mathrm{mL}$ BMP4 compared to the control (Fig. 3A). Similarly, the transcripts of male germ cell-specific genes, including Vasa and Kit, and meiotic germ cell marker $S_{c p} 1$ were expressed at highest levels in EBs with $100 \mathrm{ng} / \mathrm{mL}$ BMP4 treatment (Fig. 3A). In addition, the transcription of Dazl, Boule and Scp1, markers of early germ cells and meiotic germ cells, was significantly upregulated in EBs treated with $50 \mathrm{ng} / \mathrm{mL}$ BMP4 compared to the control (Fig. 3A).

We next probed the impact of BMP4 on the expression of germ cell-specific proteins in EBs derived from iPS cells. Western blots showed that exposure of iPS cells to BMP4 at $10-100 \mathrm{ng} / \mathrm{mL}$ led to higher expression levels of PGC marker (PRDM1), germ cell hallmarks (VASA and DAZL) and spermatogonial markers (UCHL1, GFRA1 and KIT) (Kwon et al. 2004, He et al. 2007) in a dose-dependent manner compared with the control (Fig. 3B and C). Collectively, these data, together with real-time PCR results, suggest that BMP4 stimulated the differentiation of iPS cells into male germ cells phenotypically.

\section{Noggin signaling blocked the differentiation of iPS cells into male germ cells}

To further determine the effect of BMP4 on male germ cell differentiation of iPS cells, iPS cell-derived EBs were treated without or with different doses of BMP4
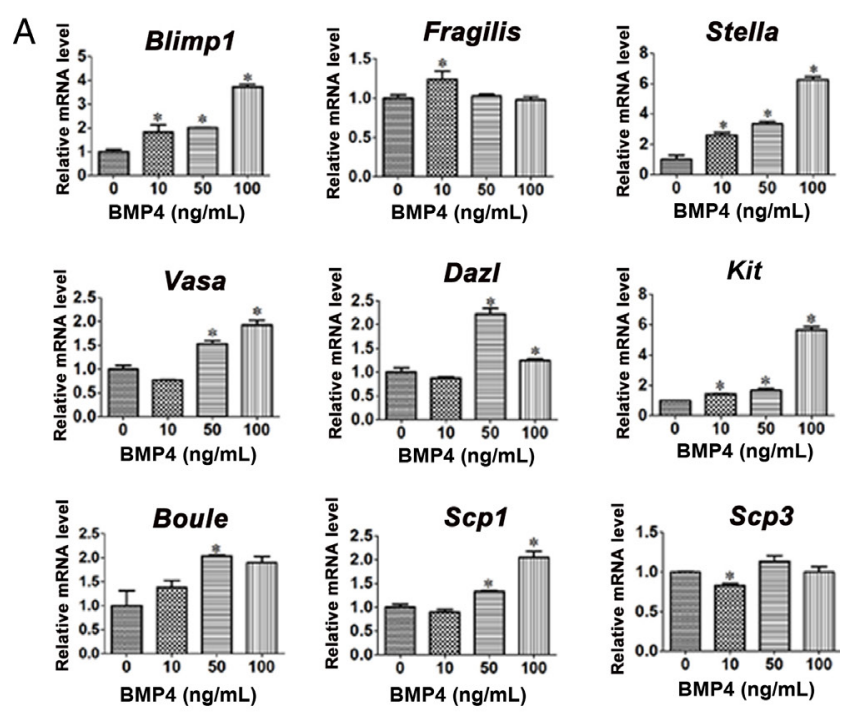

B

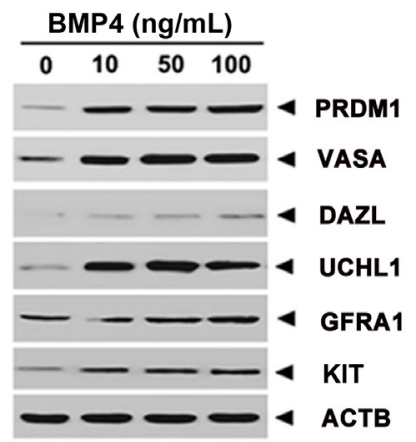

C

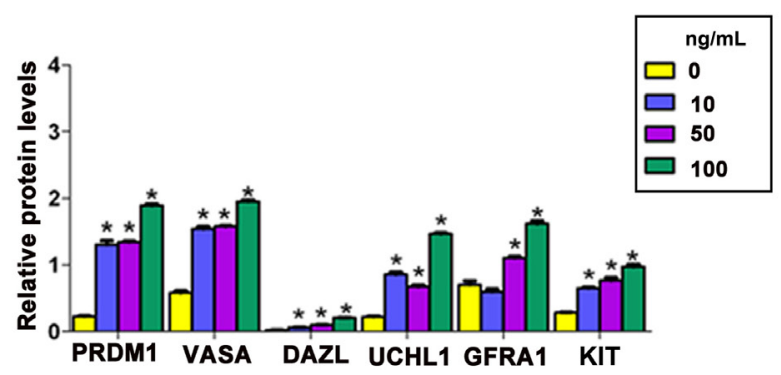

Figure 3 The effect of various concentrations of BMP4 signaling on the differentiation of mouse iPS cells into male germ cells. (A) Realtime PCR showed the transcripts of Blimp1, Fragilis, Stella, Vasa, Dazl, Kit, Boule, Scp1 and Scp3 in EBs treated without or with 10, 50 and $100 \mathrm{ng} / \mathrm{mL}$ BMP4. (B) Western blots displayed PRDM1, VASA, DAZL, UCHL1, GFRA1 and KIT protein expression in EBs treated with $0,10,50$ and $100 \mathrm{ng} / \mathrm{mL}$ BMP4. ACTB was used as the control of loading proteins. (C) Quantification of PRDM1, VASA, DAZL, UCHL1, GFRA1 and KIT protein expression relative to ACTB in EBs treated with different doses of BMP4. Relative band intensities were calculated by densitometry normalized to ACTB. Data were presented with mean \pm S.E.M. from three independent experiments. ${ }^{*} P<0.05$ represented significant differences in BMP4-treated EBs compared to the control.

antagonist, namely Noggin $(10,50$ and $100 \mathrm{ng} / \mathrm{mL}$ ) to assess the expression changes of germ cell-specific genes and proteins. Real-time PCR showed that the expression of Stella, Dazl and Scp3 were significantly reduced in EBs 
treated with $100 \mathrm{ng} / \mathrm{mL}$ Noggin (Fig. 4A). Meanwhile, no obvious change was observed in the expression of other germ cell-specific genes, e.g. Blimp1, Fragilis, Vasa, Kit, Boule and Scp1 (Fig. 4A).

We also evaluated the effect of Noggin on protein expression of germ cell markers in EBs. Western blots displayed that the translation of almost all germ cellspecific markers, including VASA, DAZL, UCHL1, GFRA1 and KIT was significantly decreased in EBs
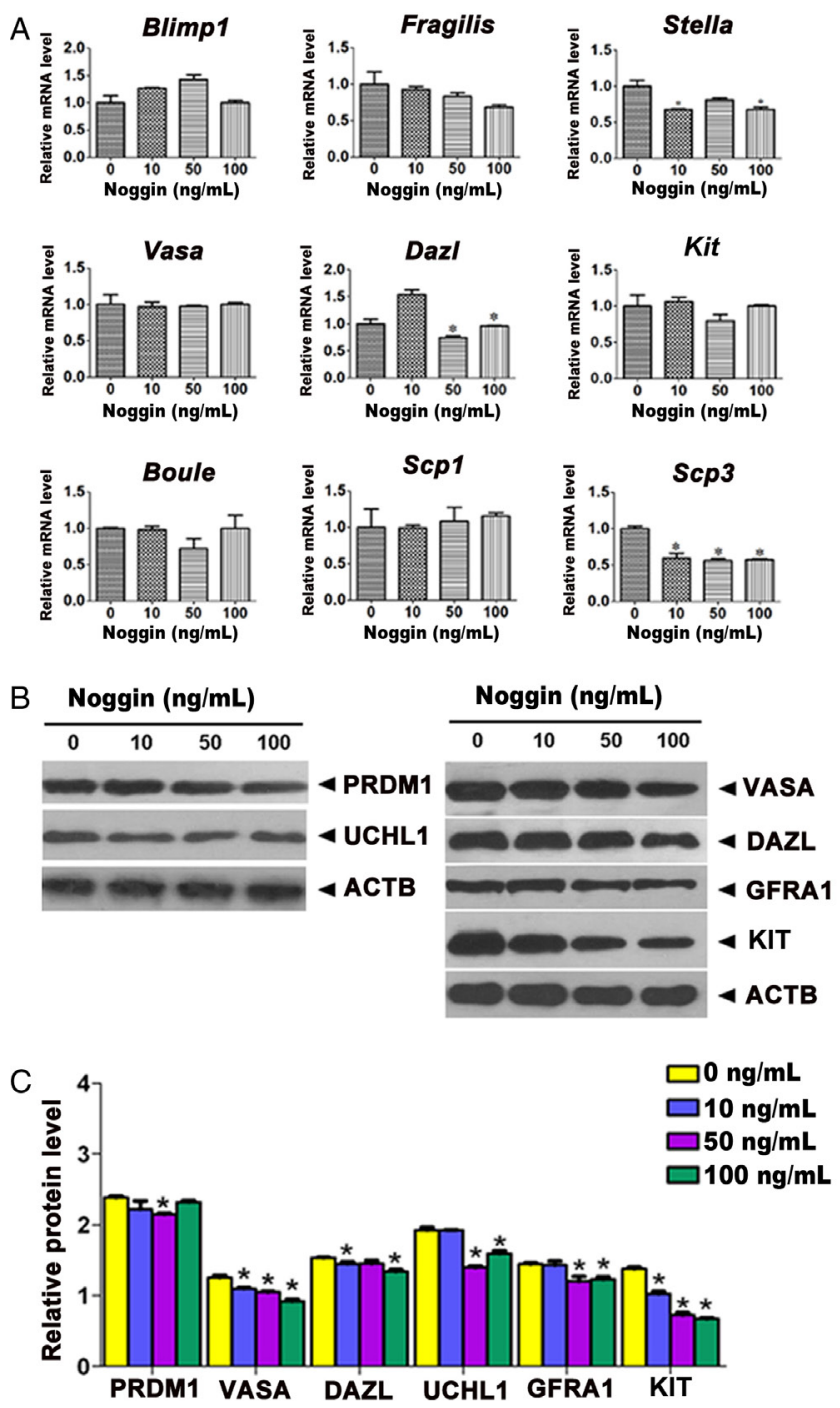

Figure 4 The influence of different concentrations of Noggin signaling on the differentiation of mouse iPS cells into male germ cells.

(A) Real-time PCR revealed Blimp1, Fragilis, Stella, Vasa, Dazl, Kit, Boule, Scp1 and Scp3 transcripts in EBs treated with 0, 10, 50 and 100 ng/mL Noggin. (B) Western blots showed PRDM1, UCHL1, VASA, DAZL, GFRA1 and KIT protein expression in EBs treated with 0, 10, 50 and $100 \mathrm{ng} / \mathrm{mL}$ Noggin. ACTB served as the control of loading proteins. (C) Quantification of PRDM1, VASA, DAZL, UCHL1, GFRA1 and KIT protein expression in EBs treated with different doses of Noggin. Relative band intensities were calculated by densitometry normalized to ACTB. Data were presented with mean \pm S.E.M. from three independent experiments. ${ }^{*} P<0.05$ represented significant differences in Noggin-treated EBs compared to the control. treated with $100 \mathrm{ng} / \mathrm{mL}$ Noggin compared to the control without Noggin (Fig. 4B and C). Therefore, $100 \mathrm{ng} / \mathrm{mL}$ Noggin was chosen as a standard dosage in further experiments. Together, these results reflect that Noggin blocks BMP4 signaling in promoting the differentiation of mouse iPS cells into male germ cells.

\section{BMP4 induced iPS cell differentiation via the Smad1/5 pathway}

We further evaluated the level of phosphorylated Smad1/5 in EBs exposed to $100 \mathrm{ng} / \mathrm{mL}$ BMP4 or $100 \mathrm{ng} / \mathrm{mL}$ Noggin. As shown in Fig. 5A and B, Smad1/5 phosphorylation was remarkably enhanced in EBs with $100 \mathrm{ng} / \mathrm{mL}$ BMP4 treatment compared to the control without treatment. In contrast, Smad1/5 phosphorylation was obviously decreased in EBs with $100 \mathrm{ng} / \mathrm{mL}$ Noggin treatment compared to BMP4-untreated control. Notably, Noggin blocked the increase of Smad1/5 phosphorylation induced by BMP4 (Fig. 5A and B). Considered together, these data indicate that BMP4 signals via the activation of Smad1/5 pathway in mouse iPS cell differentiation into male germ cells.

\section{Gata4 transcription was activated during the differentiation of iPS cells to male germ cells}

To determine which transcription factors were involved in the BMP4-induced male germ cell generation from iPS cells, we further determined the mRNA levels of several transcription factors in $\mathrm{EBs}$ treated with $100 \mathrm{ng} / \mathrm{mL}$ BMP4 or Noggin. As shown in Fig. 5C, BMP4 significantly enhanced the expression of Gata4, whereas Noggin counteracted the increases of Gata4. There was no obvious change with mRNA of Fos, whereas BMP4 diminished the transcripts of Crebbp and Jun (Fig. 5C). Therefore, transcription factor Gata4 might be involved in the BMP4-induced male germ cell differentiation of iPS cells.

\section{Id1 and Id2 were the targets of BMP signaling in iPS cells}

Id family genes might be the targets of BMPs signaling pathway (Hollnagel et al. 1999), we finally asked whether BMP4 induced the transcripts of Id family genes during the differentiation of iPS cells into male germ cells. As shown in Fig. 5D, the transcripts of $l d 1, I d 2$, $I d 3$ and $/ d 4$ were increased in EBs exposed to $100 \mathrm{ng} / \mathrm{mL}$ BMP4 compared to those in EBs without treatment. Notably, Noggin blocked the expression of $I d 1$ and $I d 2$ but enhanced the expression of Id4. Meanwhile, no significant difference of $I d 3$ expression was observed between the control and Noggin-treated EBs. Taken together, these data implicate that $I d 1$ and $I d 2$ might be the targeting genes of BMP4 in inducing male germ cell formation from iPS cells. 


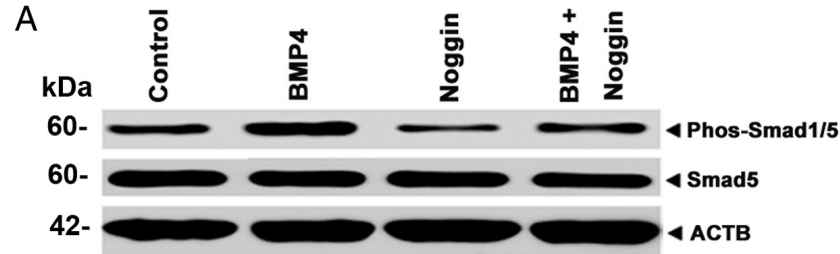

B

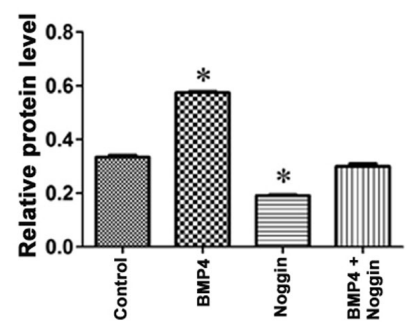

C
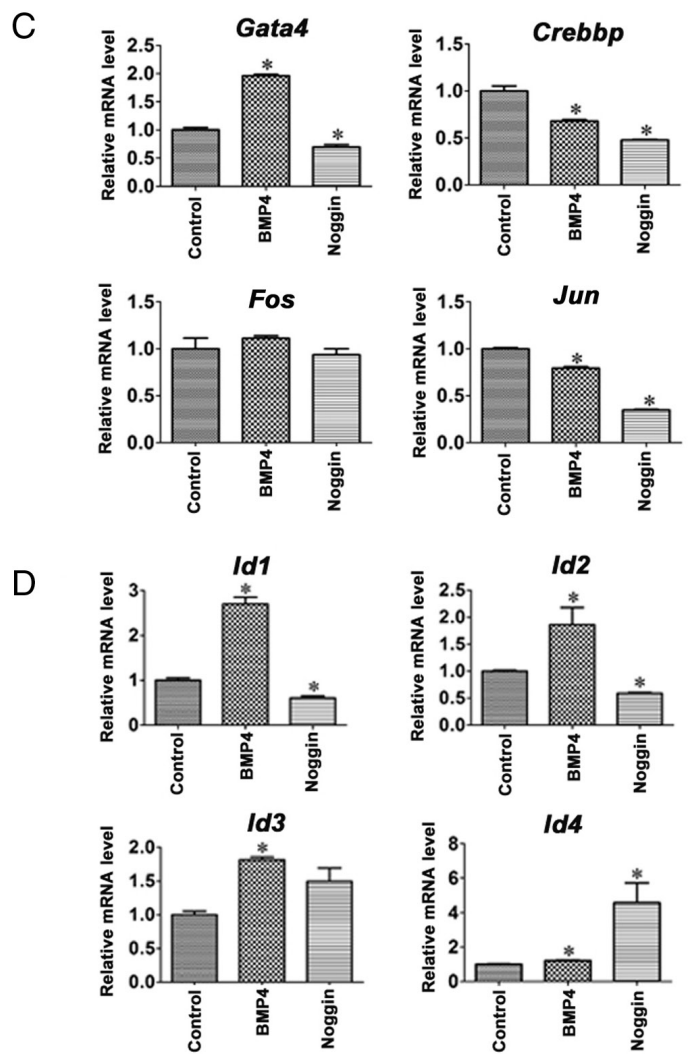

Figure 5 Expression of Smad1/5 phosphorylation, Gata4, Crebbp, Fos and Jun transcription as well as $I d 1, I d 2 I d 3$ and $I d 4$ in EBs derived from mouse iPS cells. (A) Western blots revealed the expression of Smad1/5 phosphorylation in EBs treated with $100 \mathrm{ng} / \mathrm{mL}$ BMP4 or $100 \mathrm{ng} / \mathrm{mL}$ Noggin. Smad5 and ACTB were used as a loading control of total proteins. (B) Quantification of phosSmad1/5 expression in EBs treated with BMP4 or Noggin. Relative band intensities were calculated by densitometry normalized to ACTB. (C) Real-time PCR displayed the transcription of Gata4, Crebbp, Fos and Jun in EBs treated with BMP4 or Noggin. (D) Realtime PCR showed the expression of $I d 1, I d 2, I d 3$ and $I d 4$ in EBs exposed to BMP4 or Noggin. Data were presented with mean \pm S.E.M. from three independent experiments. ${ }^{*} P<0.05$ represented significant differences in BMP4-or Noggin-treated EBs compared with the control.

\section{Discussion}

In the past decades, numerous studies have shown the generation of male germ cells from ES cells and iPS cells (West et al. 2010, Hayashi et al. 2011, Panula et al. 2011). Despite the potential tumor-forming risks and genetic aberration, iPS cells hold a great promise to shed novel insights into germ cell development due to fewer ethical issues and sufficient cells (Singh et al. 2015). However, little is known about the molecular mechanisms underlying male germ cell differentiation from pluripotent stem cells. BMP4 has been suggested to be involved in regulating self-renewal and inducing germ cell differentiation of both ES cells and iPS cells, but the exact roles and signaling transduction pathway of BMP4 in directing male germ cell formation from these cells are still unclear. In this study, mouse iPS cells were used as a model to examine the function and molecular mechanisms of BMP4 signaling in controlling male germ cell development. We found that the transcripts and protein of BMP4 and its three receptors were present in mouse iPS cells, suggesting that BMP4 acts via an autocrine pathway in these cells, which is similar to mouse ES cells (Ying et al. 2003).

To further uncover the function of BMP4 in regulating male germ cell differentiation of mouse iPS cells, expression levels of germ cell genes and proteins at different developmental stages were evaluated in BMP4- or Noggin-treated EBs. We found that BMP4 could enhance the expression of PGC-specific markers, including Blimp1, Fragilis, Stella and PRDM1, reflecting that BMP4 induced the generation of PGCs from mouse iPS cells, which was consistent with previous findings (Park et al. 2009, Panula et al. 2011). Interestingly, the expression levels of a number of hallmarks for germ cells, spermatogonia and spermatocytes, including VASA, DAZL (Kee et al. 2009), KIT (Pellegrini et al. 2003, West et al. 2010, Barrios et al. 2012), UCHL1 (He et al. 2010), GFRA1 (He et al. 2007), Boule (Kee et al. 2009), Scp1 and Scp3 (Yang et al. 2014), were increased by BMP4 in a dose-dependent manner, implicating that BMP4 was able to stimulate male germ cell formation of mouse iPS cells.

BMPs antagonist Noggin can be activated with BMP treatment in many cell types, e.g. neural precursor cells and mouse pre-osteoblastic cells, to counteract BMP signaling (Wang et al. 2010, Krause et al. 2011). To further explore the role of BMP4 signaling in mediating germ cell differentiation of pluripotent stem cells, iPS cell-derived EBs were treated with different concentrations of Noggin. Our data showed that the transcripts of several germ cell-specific genes, e.g. Stella, Dazl and Scp3 were decreased by Noggin, and notably, the translation of numerous germ cell-specific markers, including VASA, DAZL, KIT, UCHL1 and GFRA1 were also reduced by Noggin. These results clearly implicate 
that BMP signaling was blocked by Noggin in mouse iPS cells and further verify that BMP4 plays an essential role in promoting male germ cell differentiation of these cells.

It remains unclear about how BMP signaling regulates cell fate decisions through downstream effectors. Smad1 and Smad5 (Smad1/5) have been suggested to be downstream effectors of BMP pathway (Zeng et al. 2010, Bragdon et al. 2011). We observed that Smad1/5 phosphorylation was upregulated in BMP4-treated EBs but downregulated in Noggin-treated EBs compared to the control, suggesting that BMP4 acts through the Smad1/5 signaling pathway. Strikingly, phosphorylation of Smad1/5 was also observed in the control group without exogenous BMP4, indicating the presence of endogenous BMP4 signaling in EBs derived from iPS cells. Several studies have reported that transcription factors Gata4 (Rojas et al. 2005, Klaus et al. 2012), Crebbp (Vlacic-Zischke et al. 2011), Fos (Wu et al. 2008) and Jun (Hollnagel et al. 1999) are involved in BMP signaling pathway. We employed real-time PCR to identify candidate transcription factors required for male germ cell differentiation of iPS cells. We found that Gata4 transcription was increased by BMP4 in mouse iPS cells. Notably, the increase of Gata4 transcript by BMP4 was blocked by Noggin, suggesting that BMP4 activates Gata4 transcription in male germ cell differentiation of iPS cells. GATA4 belongs to the GATA family of zinc finger transcription factor, which plays crucial roles in heart, reproductive system, gastrointestinal system, respiratory system and carcinogenesis (Suzuki 2011). Previous studies have shown that Gata4 is a downstream transcription factor for BMP4 signaling (Rojas et al. 2005, Guemes et al. 2014), which is in agreement with the observations in our study. In addition, we identified that Fos, Crebbp and Jun were not the targeting transcription factors of BMP4 in mouse iPS cells.

The members of Id gene family have been demonstrated to be dominant targets of BMP/Smad signaling (Hollnagel et al. 1999, Ying et al. 2003, Li et al. 2012). Significantly, we found that the transcripts of $I d 1$ and Id 2 were remarkably enhanced by BMP4 and suppressed by Noggin, which suggests that $I d 1$ and $I d 2$ are the targeting genes involved in BMP4-induced male germ cell differentiation of mouse iPS cells. However, the expression pattern of Id gene family in this study was different from those of previous findings (Hollnagel et al. 1999, Ruzinova \& Benezra 2003), which may be due to the cell-type-specific manner of Id genes in response to BMP treatment. Interestingly, Id 4 expression displayed a distinct pattern from those of $I d 1, I d 2$ and $I d 3$, implying that the molecular pathways regulated by Id 4 are not similar to those regulated by $I d 1, I d 2$ and $I d 3$, which was consistent with previous observations (Patel et al. 2015, Sharma et al. 2015). Further investigation on the role of GATA4 and ID family members in regulating the

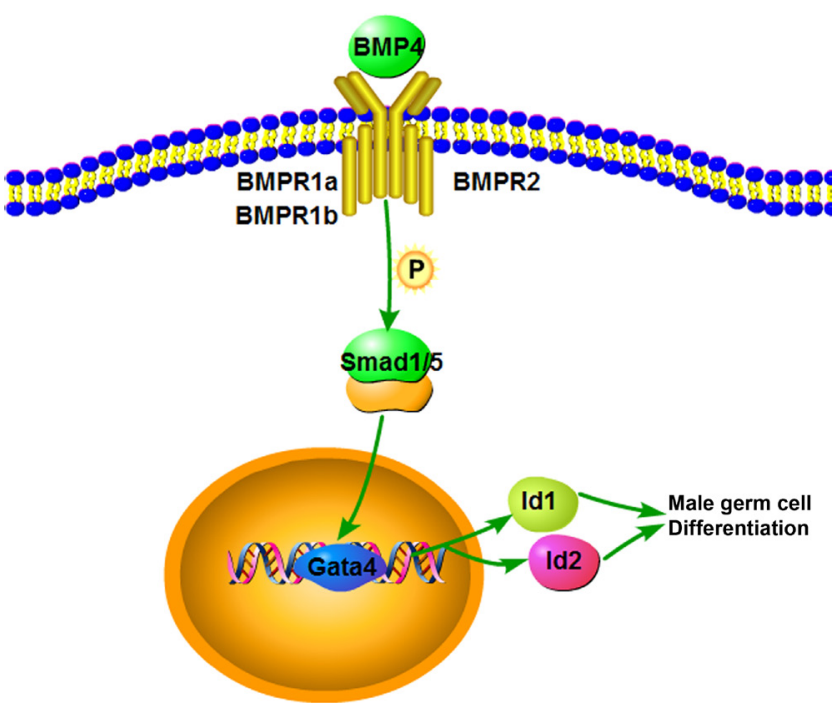

Figure 6 The schematic diagram illustrated the transduction of BMP4 signaling pathway in the differentiation of mouse iPS cells into male germ cells. ' $P$ ' indicated 'phosphorylate'.

differentiation of mouse and human iPS cells into male germ cells needs to be clarified.

\section{Conclusion}

In conclusion, we have for the first time demonstrated that mouse iPS cells express BMP4 and its multiple receptors and BMP4 promotes male germ cell differentiation of iPS cells via Smad1/5 pathway and the activation of Gata4, Id 1 and $I d 2$ pathway. The signaling transduction pathway of BMP4 has been illustrated in Fig. 6. Briefly, BMP4 initiates signaling by binding to BMPR1a, BMPR1b and BMPR2, which activates Smad1 and 5. The phosphorylated Smad1 and 5 translocates into the nucleus to upregulate the transcripts of transcription factors Gata4 and target genes Id 1 and Id2. This study thus provides novel insights into molecular mechanisms underlying male germ cell differentiation of pluripotent stem cells. It would be interesting to probe whether BMP4 stimulates the differentiation of human iPS cells and human ES cells into male germ cells through the Smad1/5/Gata4/Id1/ld2 pathway.

\section{Declaration of interest}

The authors declare that there is no conflict of interest that could be perceived as prejudicing the impartiality of the research reported.

\section{Funding}

This work was supported by grants from National Science Foundation of China (31201109, 31671550, 31171422, 31401250), key grants from National Nature Science 
Foundation of China (31230048) and Chinese Ministry of Science and Technology (2016YFC1000606, 2014CB943101), The Program for Professor of Special Appointment (Eastern Scholar) at Shanghai Institutions of Higher Learning (2012.53), Shanghai Municipal Education Commission-Gaofeng Clinical Medicine Grant Support (20152511), a grant from Shanghai Hospital Development Center (SHDC12015122), a key grant from the Science and Technology Commission of Shanghai Municipality (12JC1405900) and Key Discipline and Specialty Foundation of Shanghai Municipal Commission of Health and Family Planning.

\section{Acknowledgements}

The authors thank Prof. Ying Jin, Shanghai Jiao Tong University School of Medicine, China, for providing mouse iPS cell line.

\section{References}

Barrios F, Filipponi D, Campolo F, Gori M, Bramucci F, Pellegrini M, Ottolenghi S, Rossi P, Jannini EA \& Dolci S 2012 SOHLH1 and SOHLH2 control Kit expression during postnatal male germ cell development. Journal of Cell Science 125 1455-1464. (doi:10.1242/jcs.092593)

Bragdon B, Moseychuk O, Saldanha S, King D, Julian J \& Nohe A 2011 Bone morphogenetic proteins: a critical review. Cellular Signalling 23 609-620. (doi:10.1016/j.cellsig.2010.10.003)

Easley CAt, Phillips BT, McGuire MM, Barringer JM, Valli H, Hermann BP, Simerly CR, Rajkovic A, Miki T, Orwig KE et al. 2012 Direct differentiation of human pluripotent stem cells into haploid spermatogenic cells. Cell Reports 2 440-446. (doi:10.1016/j.celrep.2012.07.015)

Fei T, Xia K, Li Z, Zhou B, Zhu S, Chen H, Zhang J, Chen Z, Xiao H, Han JD et al. 2010 Genome-wide mapping of SMAD target genes reveals the role of BMP signaling in embryonic stem cell fate determination. Genome Research 20 36-44. (doi:10.1101/gr.092114.109)

Guemes M, Garcia AJ, Rigueur D, Runke S, Wang W, Zhao G, Mayorga VH, Atti E, Tetradis S, Peault B et al. 2014 GATA4 is essential for bone mineralization via ERalpha and TGFbeta/BMP pathways. Journal of Bone and Mineral Research 29 2676-2687. (doi:10.1002/jbmr.2296)

Guo Y, Hai Y, Yao C, Chen Z, Hou J, Li Z \& He Z 2015 Long-term culture and significant expansion of human Sertoli cells whilst maintaining stable global phenotype and AKT and SMAD1/5 activation. Cell Communication and Signaling 13 20. (doi:10.1186/s12964-015-0101-2)

Hayashi K \& Surani MA 2009 Self-renewing epiblast stem cells exhibit continual delineation of germ cells with epigenetic reprogramming in vitro. Development 136 3549-3556. (doi:10.1242/dev.037747)

Hayashi K, Ohta H, Kurimoto K, Aramaki S \& Saitou M 2011 Reconstitution of the mouse germ cell specification pathway in culture by pluripotent stem cells. Cell 146 519-532. (doi:10.1016/j.cell.2011.06.052)

He Z, Jiang J, Hofmann MC \& Dym M 2007 Gfra1 silencing in mouse spermatogonial stem cells results in their differentiation via the inactivation of RET tyrosine kinase. Biology of Reproduction 77 723-733. (doi:10.1095/biolreprod.107.062513)

He Z, Kokkinaki M, Jiang J, Dobrinski I \& Dym M 2010 Isolation, characterization, and culture of human spermatogonia. Biology of Reproduction 82 363-372. (doi:10.1095/biolreprod.109.078550)

Hiller M, Liu C, Blumenthal PD, Gearhart JD \& Kerr CL 2011 Bone morphogenetic protein 4 mediates human embryonic germ cell derivation. Stem Cells and Development 20 351-361. (doi:10.1089/ scd.2010.0084)

Hollnagel A, Oehlmann V, Heymer J, Ruther U \& Nordheim A 1999 Id genes are direct targets of bone morphogenetic protein induction in embryonic stem cells. Journal of Biological Chemistry 274 19838-19845. (doi:10.1074/jbc.274.28.19838)

Hu J, Chen YX, Wang D, Qi X, Li TG, Hao J, Mishina Y, Garbers DL \& Zhao GQ 2004 Developmental expression and function of Bmp4 in spermatogenesis and in maintaining epididymal integrity. Developmental Biology 276 158-171. (doi:10.1016/j.ydbio.2004.08.034)
Itman C \& Loveland KL 2008 SMAD expression in the testis: an insight into BMP regulation of spermatogenesis. Developmental Dynamics $\mathbf{2 3 7}$ 97-111. (doi:10.1002/dvdy.21401)

Kee K, Angeles VT, Flores M, Nguyen HN \& Reijo Pera RA 2009 Human DAZL, DAZ and BOULE genes modulate primordial germ-cell and haploid gamete formation. Nature 462 222-225. (doi:10.1038/ nature08562)

Kerr CL \& Cheng L 2010 The dazzle in germ cell differentiation. Journal of Molecular Cell Biology 2 26-29. (doi:10.1093/jmcb/mjp041)

Klaus A, Muller M, Schulz H, Saga Y, Martin JF \& Birchmeier W 2012 Wnt/ beta-catenin and Bmp signals control distinct sets of transcription factors in cardiac progenitor cells. PNAS 109 10921-10926. (doi:10.1073/ pnas.1121236109)

Krause C, Guzman A \& Knaus P 2011 Noggin. International Journal of Biochemistry and Cell Biology 43 478-481. (doi:10.1016/j. biocel.2011.01.007)

Kwon J, Wang YL, Setsuie R, Sekiguchi S, Sakurai M, Sato Y, Lee WW, Ishii Y, Kyuwa S, Noda M et al. 2004 Developmental regulation of ubiquitin C-terminal hydrolase isozyme expression during spermatogenesis in mice. Biology of Reproduction 71 515-521. (doi:10.1095/biolreprod.104.027565)

Li Z \& Chen YG 2013 Functions of BMP signaling in embryonic stem cell fate determination. Experimental Cell Research 319 113-119. (doi:10.1016/j.yexcr.2012.09.016)

Li C, Yu H, Ma Y, Shi G, Jiang J, Gu J, Yang Y, Jin S, Wei Z, Jiang H et al. 2009 Germline-competent mouse-induced pluripotent stem cell lines generated on human fibroblasts without exogenous leukemia inhibitory factor. PLOS ONE 4 e6724. (doi:10.1371/journal.pone.0006724)

Li Z, Fei T, Zhang J, Zhu G, Wang L, Lu D, Chi X, Teng Y, Hou N, Yang X et al. 2012 BMP4 Signaling Acts via dual-specificity phosphatase 9 to control ERK activity in mouse embryonic stem cells. Cell Stem Cell 10 171-182. (doi:10.1016/j.stem.2011.12.016)

Li P, Hu H, Yang S, Tian R, Zhang Z, Zhang W, Ma M, Zhu Y, Guo X, Huang Y et al. 2013 Differentiation of induced pluripotent stem cells into male germ cells in vitro through embryoid body formation and retinoic acid or testosterone induction. BioMed Research International 2013 608728. (doi:10.1155/2013/474272)

Lim JJ, Shim MS, Lee JE \& Lee DR 2014 Three-step method for proliferation and differentiation of human embryonic stem cell (hESC)-derived male germ cells. PLoS ONE 9 e90454. (doi:10.1371/ journal.pone.0090454)

Liu Y, Niu M, Yao C, Hai Y, Yuan Q, Guo Y, Li Z \& He Z 2015 Fractionation of human spermatogenic cells using STA-PUT gravity sedimentation and their miRNA profiling. Scientific Reports $\mathbf{5}$ 8084. (doi:10.1038/ srep08084)

Panula S, Medrano JV, Kee K, Bergstrom R, Nguyen HN, Byers B, Wilson KD, Wu JC, Simon C, Hovatta O et al. 2011 Human germ cell differentiation from fetal- and adult-derived induced pluripotent stem cells. Human Molecular Genetics 20 752-762. (doi:10.1093/hmg/ ddq520)

Park TS, Galic Z, Conway AE, Lindgren A, van Handel BJ, Magnusson M, Richter L, Teitell MA, Mikkola HK, Lowry WE et al. 2009 Derivation of primordial germ cells from human embryonic and induced pluripotent stem cells is significantly improved by coculture with human fetal gonadal cells. Stem Cells 27 783-795. (doi:10.1002/ stem.13)

Patel D, Morton DJ, Carey J, Havrda MC \& Chaudhary J 2015 Inhibitor of differentiation 4 (ID4): From development to cancer. Biochimica et Biophysica Acta 1855 92-103. doi:10.1016/j.bbcan.2014.12.002

Pellegrini M, Grimaldi P, Rossi P, Geremia R \& Dolci S 2003 Developmental expression of BMP4/ALK3/SMAD5 signaling pathway in the mouse testis: a potential role of BMP4 in spermatogonia differentiation. Journal of Cell Science 116 3363-3372. (doi:10.1242/jcs.00650)

Ramathal C, Durruthy-Durruthy J, Sukhwani M, Arakaki JE, Turek PJ, Orwig KE \& Reijo Pera RA 2014 Fate of iPSCs derived from azoospermic and fertile men following xenotransplantation to murine seminiferous tubules. Cell Reports 7 1284-1297. (doi:10.1016/j.celrep.2014.03.067)

Rojas A, De Val S, Heidt AB, Xu SM, Bristow J \& Black BL 2005 Gata4 expression in lateral mesoderm is downstream of BMP4 and is activated directly by Forkhead and GATA transcription factors through a distal enhancer element. Development 132 3405-3417. (doi:10.1242/ dev.01913) 
Ruzinova MB \& Benezra R 2003 Id proteins in development, cell cycle and cancer. Trends in Cell Biology 13 410-418. (doi:10.1016/S09628924(03)00147-8)

Saitou M \& Yamaji M 2010 Germ cell specification in mice: signaling, transcription regulation, and epigenetic consequences. Reproduction 139 931-942. (doi:10.1530/REP-10-0043)

Saitou M, Payer B, O'Carroll D, Ohinata Y \& Surani MA 2005 Blimp1 and the emergence of the germ line during development in the mouse. Cell Cycle 4 1736-1740. (doi:10.4161/cc.4.12.2209)

Sharma P, Chinaranagari S \& Chaudhary J 2015 Inhibitor of differentiation 4 (ID4) acts as an inhibitor of ID-1, -2 and -3 and promotes basic helix loop helix (bHLH) E47 DNA binding and transcriptional activity. Biochimie 112 139-150. (doi:10.1016/j.biochi.2015.03.006)

Shi Y \& Massague J 2003 Mechanisms of TGF-beta signaling from cell membrane to the nucleus. Cell 113 685-700. (doi:10.1016/S00928674(03)00432-X)

Silva C, Wood JR, Salvador L, Zhang Z, Kostetskii I, Williams CJ \& Strauss JF III 2009 Expression profile of male germ cell-associated genes in mouse embryonic stem cell cultures treated with all-trans retinoic acid and testosterone. Molecular Reproduction and Development 76 11-21. (doi:10.1002/mrd.20925)

Singh VK, Kalsan M, Kumar N, Saini A \& Chandra R 2015 Induced pluripotent stem cells: applications in regenerative medicine, disease modeling, and drug discovery. Frontiers in Cell and Developmental Biology 3 2. (doi:10.3389/fcell.2015.00002)

Suzuki YJ 2011 Cell signaling pathways for the regulation of GATA4 transcription factor: Implications for cell growth and apoptosis. Cellular Signalling 23 1094-1099. (doi:10.1016/j.cellsig.2011.02.007)

Varga AC \& Wrana JL 2005 The disparate role of BMP in stem cell biology. Oncogene 24 5713-5721. (doi:10.1038/sj.onc.1208919)

Vlacic-Zischke J, Hamlet SM, Friis T, Tonetti MS \& Ivanovski S 2011 The influence of surface microroughness and hydrophilicity of titanium on the up-regulation of TGFbeta/BMP signalling in osteoblasts. Biomaterials 32 665-671. (doi:10.1016/j.biomaterials.2010.09.025)

Wang L, Zhang X, Guo Y, Chen X, Li R, Liu L, Shi C, Guo C \& Y Zhang 2010 Involvement of BMPs/Smad signaling pathway in mechanical response in osteoblasts. Cellular Physiology and Biochemistry 26 1093-1102. (doi:10.1159/000323987)
Wei W, Qing T, Ye X, Liu H, Zhang D, Yang W \& Deng H 2008 Primordial germ cell specification from embryonic stem cells. PLoS ONE 3 e4013. (doi:10.1371/journal.pone.0004013)

West JA, Park IH, Daley GQ \& Geijsen N 2006 In vitro generation of germ cells from murine embryonic stem cells. Nature Protocols 1 2026-2036. (doi:10.1038/nprot.2006.303)

West FD, Roche-Rios MI, Abraham S, Rao RR, Natrajan MS, Bacanamwo M \& Stice SL 2010 KIT ligand and bone morphogenetic protein signaling enhances human embryonic stem cell to germ-like cell differentiation. Human Reproduction 25 168-178. (doi:10.1093/humrep/dep338)

Wu JB, Fong YC, Tsai HY, Chen YF, Tsuzuki M \& Tang CH 2008 Naringininduced bone morphogenetic protein-2 expression via PI3K, Akt, c-Fos/cJun and AP-1 pathway in osteoblasts. European Journal of Pharmacology 588 333-341. (doi:10.1016/j.ejphar.2008.04.030)

Yang S, Bo J, Hu H, Guo X, Tian R, Sun C, Zhu Y, Li P, Liu P, Zou S et al. 2012 Derivation of male germ cells from induced pluripotent stem cells in vitro and in reconstituted seminiferous tubules. Cell Proliferation 45 91-100. (doi:10.1111/j.1365-2184.2012.00811.x)

Yang S, Ping P, Ma M, Li P, Tian R, Yang H, Liu Y, Gong Y, Zhang Z, Li Z et al. 2014 Generation of haploid spermatids with fertilization and development capacity from human spermatogonial stem cells of cryptorchid patients. Stem Cell Reports 3 663-675. (doi:10.1016/j. stemcr.2014.08.004)

Ying QL, Nichols J, Chambers I \& Smith A 2003 BMP induction of Id proteins suppresses differentiation and sustains embryonic stem cell selfrenewal in collaboration with STAT3. Cell 115 281-292. (doi:10.1016/ S0092-8674(03)00847-X)

Zeng S, Chen J \& Shen H 2010 Controlling of bone morphogenetic protein signaling. Cellular Signalling 22 888-893. (doi:10.1016/j. cellsig.2009.12.007)

Received 31 May 2016

First decision 4 July 2016

Revised manuscript received 27 October 2016

Accepted 18 November 2016 